\title{
VULNERABILITY CONCEPTS AND ITS APPLICATION IN VARIOUS FIELDS: A REVIEW ON GEOGRAPHICAL PERSPECTIVE
}

\author{
Shitangsu Kumar Paul \\ Department of Geography and Environmental Studies, University of Rajshahi \\ Rajshahi-6205, Bangladesh \\ e-mail: shitangsuk@yahoo.com, spaulrajbd@gmail.com
}

\begin{abstract}
Vulnerability has no universal definition. Experts from various disciplines use the concept and define vulnerability, which leads diverse measuring methods to serve their own purpose and interests. Approaches to define vulnerability vary among the disciplines because of the various components of risk, household response and welfare outcomes. The objective of this paper is to present an overview based on available scientific literature from various disciplines to examine the origin, evolution and use of the vulnerability concept across different field of studies. Vulnerability is exclusively used in various disciplines such as geography, anthropology, economics, ecology, public health, poverty and development, sustainable livelihoods, famine and food security, sustainability science, land management, disaster management and climate change. Therefore, different disciplines have their own reasons for defining, measuring and developing conceptual models of vulnerability; hence there is no reason to presume that concepts, measures and methods will be universal across the disciplines. Lessons learned from one area may not be equally suitable for all. Hence, differences between various fields need to be bridged by a holistic approach and multidisciplinary research cooperation, and geography as a unique multidisciplinary field of study has the major disciplinary legitimacy to fill up the gaps and to create a common platform to work together in vulnerability research among the various research traditions.
\end{abstract}

Key words: Vulnerability, risk, human ecology, disaster, climate change, geography.

সারাংশ: বিপন্নতার সর্বজনগ্রাহ্য কোন সংজ্ঞা নেই। বিভিন্ন ডিসিপ্লিনের বিশেষজ্ঞগণ এ ধারণাটি ব্যবহার করে এবং বিপন্নতাকে সংজ্ঞায়িত করে, যা নিজস্ব লক্ষ্য ও উদ্দেশ্য পূরণের জন্য ভিন্ন পরিমাপ পদ্ধতির উদ্ভাবন করেন। ঝুঁকির বিভিন্ন উপাদান, খানার প্রতিক্রিয়া এবং কল্যাণ সাধনের জন্য বিপন্নতাকে সংজ্ঞায়িত করার দৃষ্টিভঙ্গিসমূহ বিভিন্ন ডিসিপ্লিনের মট্যে পৃথক হয়। এই প্রবন্ধের উদ্দেশ্য হল বিভিন্ন ডিসিপ্লিনের সমসাময়িক বৈজ্ঞানিক গবেষণা হতে প্রাপ্ত জ্ঞান দ্বারা বিপন্নতা ধারণার উৎপত্ত, বিবর্তন এবং বিভিন্ন পঠিত বিষয়ে কিভাবে ব্যবহৃত হয় তা নিরীক্ষা করা। বিপন্নতা স্বতন্ত্রভাবে বিভিন্ন ডিসিপ্লিনে ব্যবহৃত হয় যেমন, ভূগোল, নৃবিজ্ঞান, অর্থনীতি, বাস্তব্যবিদ্যা, জনস্বাস্থ্য, দারিদ্রতা এবং উন্নয়ন, টেকসই জীবিকা, দূর্ভিক্ষ এবং খাদ্য নিরাপত্তা, টেকসই বিজ্ঞান, ভূমি ব্যবস্থাপনা, দুর্ত্যোগ ব্যবস্থাপনা এবং জলবায়ু পরিবর্তন। এ জন্য বিপন্নতাকে সংজ্ঞায়িত করা, পরিমাপ করা এবং কল্পনাপ্রসুত মড়ে তৈরি করার ক্ষেত্রে বিভিন্ন ডিসিপ্লিনের নিজস্ব কারণ রয়েছে। এ জন্য এটা মনে করার কোন কারণ নেই যে, বিপন্নতার ধারণা, পরিমাপ এবং পদ্ধতি বিভিন্ন ডিসিপ্লিনের মধ্যে সর্বজনগ্রাহ্য হবে। একটি বিষয় থেকে অর্জিত জ্ঞান সকল বিষয়ের ক্ষেত্রে সমভাবে উপযোগী নাও হতে পারে। এজন্য বিভিন্ন বিষয়ের মট্যে যে পার্থক্যসমূহ রয়েছে সেগুলো সামগ্রিক দৃষ্টিভঙ্গি এবং মাল্টিডিসিপ্লিনারি গবেষণা সহযোগিতার মাধ্যমে সেতুবন্ধন রচনা করা প্রয়োজনীয়। ভূগোল একটি মাল্টিডিসিপ্লিনারি বিষয় হওয়ায় এর প্রধান বিষয়গত বৈধতা রয়েছে এই শূণ্যস্থান পূরণ করা এবং একটি সাধারণ মঞ্চ তৈরি করা যেখানে বিপন্নতা নিয়ে গবেষণাকারী বিভিন্ন গবেষণা প্রথা একত্রে কাজ করতে পারে।

\section{Introduction}

Vulnerability is defined as an internal risk factor of the subject or a system that is exposed to a hazard and corresponds to its intrinsic tendency to be affected, or susceptible to damage. It represents the physical, economic, social susceptibility or tendency of a community to damage in the case a threatening circumstances of natural or anthropogenic origin (Cardona, 2003; Emrich and Cutter, 2011). In general sense, vulnerability can be defined as the inability of a system to withstand against the perturbations of external stressors. It is a concept that has been used in different research backgrounds (Adger, 2006; Smit and Wandel, 2006) but there is no consensus on its meaning and definitions (Hufschmidt, 2011). Based on the research interest, the term has been applied exclusively to the societal, ecological, natural, or biophysical subsystem or to the socio-ecological system (Gallopin, 2006). Therefore, practitioners from different disciplines use different meanings and concepts of vulnerability, which ultimately led to diverse methods of defining and measuring. The differences in concepts of vulnerability among the various disciplines can be explained by their interest to focus on different components of risk, household responses to risk and welfare outcomes. The disciplines include geography, economics, food security, asset-based and sustainable livelihoods, sociology, anthropology, disaster management, environmental science, and health and nutrition (Alwang, et al., 2001).

The scientific use of vulnerability is deeply rooted in geography and natural hazard science; moreover the term is increasingly being used as a central concept in various other traditions such as ecology, public health, poverty and development, secure livelihoods and famine, sustainability science, land change, and climate impacts and adaptation. The term is used in various ways by the scientists from different knowledge areas, and even within the same research area. For example, natural scientists and engineers use the term in a descriptive ways while social scientists use it in a specific explanatory model (O’Brien, et al., 2004; Gow, 2005). However, within the geography the term vulnerability is being increasingly used after the Timmerman's conceptualization that "vulnerability is a term of such broad use as to be almost useless for 
careful description at the present, except as a rhetorical indicator of areas of greatest concern"' (Timmermann, 1981). On the other hand, Liverman (1990) mentioned that vulnerability "has been related or equated to concepts such as resilience, marginality, susceptibility, adaptability, fragility, and risk'. Currently, vulnerability is used in the field of global change, environment and development studies. Within the last few years, especially urban vulnerability and the vulnerability of mega-cities became a focal point of discussion among urban geographers (Anderson, 1992; Jones and Kandel, 1992; Mitchell, 1998). However, according to Cutter (1996) vulnerability has no common conceptualization and its meaning is still unclear. Vulnerability can be personal or individual level both in spatial and non-spatial realms. Social vulnerability includes susceptibility of social groups or society to potential losses from extreme events and the ability to absorb and withstand impacts (Emrich and Cutter, 2011). Besides, in technical sense, vulnerability can also exist for a house, an electricity grid, or transport infrastructure. Finally, there is a potential for loss derived from the interaction of society with biophysical conditions which in turn affect the resilience of the environment to respond to the hazard or disaster as well as influencing the adaptation of society to such changing conditions. Therefore, many of the discrepancies in the meanings of vulnerability arise from different epistemological orientations and subsequent methodological practices. Also, there is considerable variation in the choice of hazards themselves (e.g. natural, chemical, technological, biological, man-made, instrumental), the scale (global versus local), and in the regions chosen for examination (developed versus developing). Nevertheless, one can find three distinct themes in vulnerability studies: these are vulnerability as risk/hazard exposure; vulnerability as social response; and vulnerability of places (Cutter, 1996). According to Cutter (1996) vulnerability as hazard of place concept combines elements of potential exposure or risk and societal coping response, but it is inherently more geographically centred. In this perspective, vulnerability is conceived as both a biophysical risk as well as a social response, but within a specific area or geographic domain.

\section{A succinct Review of Vulnerability: Conceptual Considerations}

A growing body of literature is available on vulnerability of bio-physical and socio-ecological realms (for comprehensive review see Timmermann, 1981; Liverman, 1990; Cutter, 1996; Hewitt, 1997; Kasperson and Kasperson, 2001; UNEP, 2002; Ford,
2002; Turner, et al., 2003a; Cardona 2003; Prowse 2003 and Kasperson, et al., 2005). Most commonly, vulnerability studies use few overlapping concepts such as vulnerability, risk, exposure, sensitivity, resilience, adaptive capacity, coping and so on (IPCC, 2001; Adger, et al., 2001; Burton, et al., 2002). These terms are in most cases not clear, indistinct and same concept is used by various scholars in different contexts (Brook, 2003). For example, hazard researchers give emphasize on the concept of risk, while social science and climate scientists prefer to apply the term vulnerability (Downing, et al., 2001; Allen, 2003). Moreover, even both social and climate scientists use the term vulnerability but often mean different things. Social scientists consider people's inability to cope together with various socio-economic factors to describe vulnerability. In contrast, climate scientists consider weather and climate related extremes as perturbation, and probability of the occurrence of such extreme events to describe vulnerability (Nicholls, et al., 1999).

In addition, vulnerability concept is social science appeared as a vital theme after Sen's research on famine and entitlement failure (Sen, 1981) followed by Chambers in development research (Chambers, 1989). Considering these pioneered work Bohle and Watts (1993ab) afterwards applied the term from development point of view. Furthermore, looking at of climatic extremes and conceptualization of vulnerability in climate change discourse were presented by Adger (1999, 2000, 2006), Adger and Kelly (1999), Bohle, et al., (1994), Downing, et al., (2001), Handmer, et al., (1999), Moss, et al., (2001), Brooks (2003), Downing and Patwardhan (2005), Kasperson, et al., (2006, 2003), Leichenko and O'Brien (2002), and O'Brien, et al., (2004). Besides, application of vulnerability tools, techniques and methods in social change, urbanization, climate change, resource management and environment are presented by various scientists such as Eakin and Luers (2006), Bankoff, et al., (2004), Pelling (2003), Fu"ssel and Klein (2006), Cutter (2003), Ionescu, et al., (2005) and Kasperson, et al., (2005). Based on the review of existing literature it reveals that common to different approaches, social vulnerability is seen as a dual process concerning exposure to risk, shocks and lack of coping capacities (USP, 2013). Moreover, hazard place based model in social vulnerability approach is considered as a unique concept, which focuses clearly on vulnerability of a location and represents the general circumstances and factors resulting to the vulnerability of a specific geographical area (Kumpulainen, 2006). Additionally, Berkes and Folke (1998) opined that 'there is no single universally 
accepted way of formulating the linkages between human and natural systems'. On the contrary, other studies considered that vulnerability is locationally driven phenomenon. In simple term, vulnerability is primarily a function of proximity to the source of risk/hazard. Therefore, Weichselgartner and Bertens (2000) have proposed the concept of the combination of the elements of hazard event and human response behaviour and thus both geographic and social space are seized. In this regard, vulnerability is considered as a combined effect of bio-physical hazard and human response with a specific geographic location (Weichselgartner, 2001). Moreover, in recent times, geographic information system and related technologies is prompting us to reconsider our understanding of vulnerability both in theoretical and practical/applied ways (Weichselgartner, 2001). Besides, maps become a more and more common tool to present vulnerability due to the increasing use by geographer, urban and regional planner, environment management, geologist, hydrologists and other experts (Preston et al., 2011). Weichselgartner (2001) for example measured hazard, exposure, preparedness, prevention and response in qualitative manner. Each factor is assessed by means of mapable indicators which obviously vary according to the scale of analysis. The overlay of each themes results in the vulnerability of specific hazard. Multi-hazard approach is also possible, however it is preferable to prepare vulnerability map of specific hazard and subsequently different vulnerability maps can be overlaid and interpreted (Preston et al., 2011).

\section{Objective of the Study}

The objectives of this paper are to gather information from various disciplines concerning the use of the term vulnerability, and outline the origin and evolution of the term across various fields, and finally present the application from geographical perspective to create a common platform for vulnerability research. In this paper an attempt has also been made to bring greater conceptual clarity to studies on vulnerability beginning with the concepts of entitlement, risk and hazard among geographers followed by application of the concepts and approaches of vulnerability among various fields and finally locate the geography as a discipline in study of vulnerability research tradition.

\section{Vulnerability: Selected Definitions}

The concept of vulnerability is deeply rooted in the field of natural hazards and poverty (Editorial, 2006). It is true that vulnerability has no universal definition, but undoubtedly it is a powerful analytical tool in describing the existing condition of susceptibility to harm, powerlessness, and marginality of both physical and socio-ecological systems. At the same time, for guiding normative analysis of measures to enhance well-being through reduction of risk (Adger, 2006). However, for clear understanding few selected definitions of vulnerability is presented in the table 1 .

Table 1 Selected Definitions of Vulnerability

\begin{tabular}{|c|c|}
\hline Author(s) & Definitions \\
\hline Gabor and Griffith (1980) & $\begin{array}{l}\text { Vulnerability is the threats (of hazardous materials) to which people are exposed (including chemical agents } \\
\text { and the ecological situation of the communities and their level of emergency preparedness). Vulnerability is the } \\
\text { risk context. }\end{array}$ \\
\hline Timmerman (1981) & $\begin{array}{l}\text { Vulnerability is the degree to which a system acts adversely to the occurrence of a hazardous event. The degree } \\
\text { and quality of the adverse reaction are conditioned by a system's resilience (a measure of the system's capacity } \\
\text { to absorb and recover from the event). }\end{array}$ \\
\hline UNDRO (1982) & $\begin{array}{l}\text { Vulnerability is the degree of loss to a given element or set of elements at risk resulting from the occurrence of a } \\
\text { natural phenomenon of a given magnitude. }\end{array}$ \\
\hline Susman et al.,. (1984) & Vulnerability is the degree to which different classes of society are differentially at risk. \\
\hline Kates (1985) & Vulnerability is the 'capacity to suffer harm and react adversely'. \\
\hline $\begin{array}{l}\text { Pijawka and Radwan } \\
\text { (1985) }\end{array}$ & $\begin{array}{l}\text { Vulnerability is the threat or interaction between risk and preparedness. It is the degree to which hazardous } \\
\text { materials threaten a particular population (risk) and the capacity of the community to reduce the risk or adverse } \\
\text { consequences of hazardous materials releases. }\end{array}$ \\
\hline Bogard (1988) & $\begin{array}{l}\text { Vulnerability is operationally defined as the inability to take effective measures to insure against losses. When } \\
\text { applied to individuals, vulnerability is a consequence of the impossibility or improbability of effective mitigation } \\
\text { and is a function of our ability to select the hazards. }\end{array}$ \\
\hline Mitchell (1998) & Vulnerability is the potential for loss. \\
\hline Liverman (1990) & $\begin{array}{l}\text { Distinguishes between vulnerability as a biophysical condition and vulnerability as defined by political, social and } \\
\text { economic conditions of society. She argued for vulnerability in geographical space (where vulnerable people and } \\
\text { places are located) and vulnerability in social space (who in that place is vulnerable). }\end{array}$ \\
\hline Downing (1991) & $\begin{array}{l}\text { Vulnerability has three connotations: it refers to a consequence (e.g. famine) rather than a cause (e.g. are } \\
\text { vulnerable to hunger); and it is a relative term that differentiates among socioeconomic groups or regions, rather } \\
\text { than an absolute measure of deprivation. }\end{array}$ \\
\hline Dow (1992) & $\begin{array}{l}\text { Vulnerability is the differential capacity of groups and individuals to deal with hazards, based on their positions } \\
\text { within physical and social worlds. }\end{array}$ \\
\hline
\end{tabular}




\begin{tabular}{|c|c|}
\hline Smith (1992) & $\begin{array}{l}\text { Risk from a specific hazard varies through time and according to changes in either (or both) physical exposure or } \\
\text { human vulnerability (the breadth of social and economic tolerance available at the same site). }\end{array}$ \\
\hline Alexander (1993) & Human vulnerability is a function of the costs and benefits of inhabited areas at risk from natural disasters. \\
\hline Cutter (1993) & $\begin{array}{l}\text { Vulnerability is the likelihood that an individual or group will be exposed to and adversely affected by a hazard. } \\
\text { It is the interaction of the hazards of place (risk and mitigation) with the social profile of communities. }\end{array}$ \\
\hline Watts and Bohle (1993) & $\begin{array}{l}\text { Vulnerability is defined in terms of exposure, capacity and potentiality. Accordingly, the prescriptive and } \\
\text { normative response to vulnerability is to reduce exposure, enhance coping capacity, strengthen recovery potential } \\
\text { and bolster damage control (i.e. minimize destructive consequences) via private and public means. }\end{array}$ \\
\hline Blaikie et al.,. (1994) & $\begin{array}{l}\text { By vulnerability we mean the characteristics of a person or group in terms of their capacity to anticipate, cope } \\
\text { with, resist, and recover from the impact of a natural hazard. It involves a combination of factors that determine } \\
\text { the degree to which someone's life and livelihood is put at risk by a discrete and identifiable event in nature or in } \\
\text { society. }\end{array}$ \\
\hline Bohle et al.,. (1994) & $\begin{array}{l}\text { Vulnerability is best defined as an aggregate measure of human welfare that integrates environmental, social, } \\
\text { economic and political exposure to a range of potential harmful perturbations. Vulnerability is a multilayered and } \\
\text { multidimensional social space defined by the determinate, political, economic and institutional capabilities of } \\
\text { people in specific places at specific times. }\end{array}$ \\
\hline Dow and Downing (1995) & $\begin{array}{l}\text { Vulnerability is the differential susceptibility of circumstances contributing to vulnerability. Biophysical, } \\
\text { demographic, economic, social and technological factors such as population ages, economic dependency, racism } \\
\text { and age of infrastructure are some factors which have been examined in association with natural hazards. }\end{array}$ \\
\hline Gilard and Givone. (1997) & $y$ represents the sensitivity of land use to the hazard phenomenon \\
\hline Comfort, et al.,. (1999) & $\begin{array}{l}\text { Vulnerability are those circumstances that place people at risk while reducing their means of response or denying } \\
\text { them available protection }\end{array}$ \\
\hline $\begin{array}{l}\text { Weichselgartner } \\
\text { and Bertens (2000) }\end{array}$ & $\begin{array}{l}\text { By vulnerability we mean the condition of a given area with respect to hazard, exposure, preparedness, prevention, } \\
\text { and response characteristics to cope with specific natural hazards. It is a measure of capability of this set of } \\
\text { elements to withstand events of a certain physical character }\end{array}$ \\
\hline Adger (2006) & $\begin{array}{l}\text { Vulnerability is the state of susceptibility to harm from exposure to stresses associated with environmental and } \\
\text { social change and from the absence of capacity to adapt. }\end{array}$ \\
\hline Ciurean, et al.,. (2013) & Vulnerability refers to the inability to withstand the effects of a hostile environment. \\
\hline Wolf, et al.,. (2013) & measure of possible future harm. \\
\hline
\end{tabular}

Source: Adopted from Cutter (1996), Weichselgartner (2001), Hogan and Marandola (2005), Adger (2006), Wolf, et al., (2013).

Nevertheless, from the above definitions, it clearly reveals that vulnerability of any system at any scale is reflective or a function of the exposure and sensitivity of that system to hazardous conditions and the ability or capacity or resilience of the system to cope, adapt or recover from the effects of those conditions (Gallopin, 2006). However, the concepts of adaptation, adaptive capacity, vulnerability, resilience, exposure and sensitivity are interrelated as well as have wide application to global change science (Smit and Wandel, 2006). The central concept related to vulnerability is exposure, meaning in general the degree, duration, and/or extent in which the system is in contact with, or subject to the perturbation (Kasperson, et al., 2005; Adger, 2006). On the contrary, sensitivity it is 'the extent to which a human or natural system can absorb shocks without suffering long-term harm or other significant state of change (Adger, 2006). Gallopin (2003) opined that 'sensitivity is the degree to which the system is modified or affected by an internal or external disturbance or set of disturbances.' Adger (2000) defines social resilience as the ability of groups or communities to cope with external stresses and disturbances as a result of social, political, and environmental change. According to Bohle et al., (1994) the space of vulnerability (i.e. risk, exposure, coping capacity and recovery potential) is demarcated by three idiosyncratic processes (figure 1) for example three sides of analytical triangle is human ecology, expanded entitlements, and political economy. The intersection of these axes creates three parallel analytical concepts which are central to the analysis of vulnerability to global climate change such as endowments, class relations and empowerment and political ecology (Figure 1).

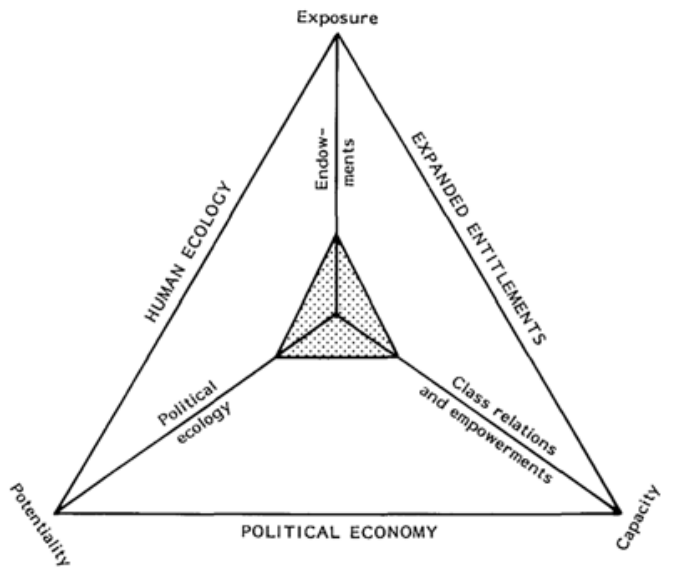

Fig. 1 The Casual Structure of Vulnerability (Adopted from Bohle et al., 1994) 


\section{Evolution of Vulnerability and its use in Different Disciplines}

In the 1990s, natural hazards scholars started to focus on the issue of vulnerability of people owing to the impacts of environmental change, especially climate change. In this case Geography provides the major disciplinary legacy. In compare to the scholars investigating the resilience of systems, there is slight focus on mathematical models by scholars who examine vulnerability, but a greater focus was on the comparative analysis of case studies (Editorial, 2006). Nonetheless, particularly human geography and human ecology have theorized vulnerability to environmental change. However, both of these disciplines have made contributions to present understanding of socialecological systems, while related insights into entitlements grounded vulnerability analysis in theories put emphasis in social change and decision-making fields (Adger, 2006). Moreover, two major antecedents' research traditions such as, the analysis of vulnerability as lack of entitlements, and the analysis of vulnerability to natural hazards are acted as basic grounds of the ideas; that eventually rendered into present research on vulnerability of social and physical systems in an integrated manner.

\section{Vulnerability in Hazard Literatures}

Vulnerability research in the hazards tradition is defined into three overlapping areas i.e. human ecology or political ecology, natural hazards, and the so-called 'Pressure and Release' model by Blaikie, et al., 1994; that covers the space between hazards and political ecology approaches (Adger, 2006). The basis of this research tradition is the physical elements of exposure and the probability of hazard impact. Burton, et al., (1978, 1993) reviewed and combined the decades of research and practiced on flood management, geohazards and major technological hazards; and shown lessons on individual perceptions of risk, through to international collective action. The authors argued that all types of natural hazards and all social and political violence have differential impacts on different groups in the society. Disasters only can take place when losses exceed the capacity of population to resist and recover. Therefore, vulnerability cannot be defined without the capacity of population to absorb, resist and recover from the impact of hazard event (Westgate and O’Keefe, 1976).

In fact, vulnerability of people to natural hazards depends on where they reside, what types of natural resource they use and above all with which resources they have to cope. Burton, et al., (1993) also argued that natural hazards are usually mediated by institutional structures, and in general increased economic activities not necessarily reduce the vulnerability to hazard impacts. However, Adger (2003) has quite different opinion, it is not only institutions rather lack of access or control over resources could mediate vulnerability. In addition, like food insecurity, vulnerability to natural hazards is often explained by technical and institutional aspects. In contrast to this approach, human ecology emphasizes the role of economic development in adapting to changing exogenous risk; and therefore differences in class structure, governance, and economic dependency has the differential impacts of hazards (Hewitt, 1983). However, these two contrary traditions of hazard research are bridged by Blaikie, et al., (1994) through 'Pressure and Release' model (Adger, 2006). In this model Blaikie, et al., (1994) and later on Wisner, et al., (2004) proposed that physical and biological hazard creates pressure and leads towards vulnerability in one hand, and further pressure derived from root causes through local geography and social differentiation that further lead to the cumulative progression of vulnerability on the other. Therefore, these two pressures culminate in the disasters that result from the additive pressures of hazard and vulnerability (Blaikie, et al., 1994). The analysis includes the essence of vulnerability derived from physical and biological and also incorporated the root causes of vulnerability within human ecology framework. Though, they have deliberatively omitted technological, geological or hazard posed by HIV/AIDS epidemic; a long wave disaster with a slow onset but catastrophic impact (Barnett and Blaikie, 1994; Stabinski, et al., 2003).

It is true that extreme events and natural disasters are gradually receiving attention to hazard researchers and considered as important factors for vulnerability analysis of specific population in a specific location (Hogan, 2002). Therefore, question comes up how specific population becomes vulnerable to a particular disaster and how such vulnerability can be reduced? In this regard, Adger (2006) has pointed out that resilience and multilevel governmental intermediations may be necessary to minimize vulnerability to disasters. Likewise, Cannon (1994) has pointed out that socioeconomic factors and access to resources together with political power influence vulnerability. In addition, both the studies also recognized the multipart circumstances that differentiate hazard from disaster. In the hazard research discourse, Cutter (1996) presented 'hazard of place model' and delivers a useful insight of viewing vulnerability in disaster situation. She considered vulnerability of a place is a combination of social 
vulnerability factors such as demographic characteristics and risk perception, and bio-physical vulnerability factor such as hazard exposure in a specific geographic location. In 'hazard of place model' Cutter (1996) and afterward Cutter, et al., (2003) has brought together various elements which creates vulnerability of place (Figure 2). In this model 'risk' is considered as 'probability of a hazard event' and 'mitigation' is activities or measures to reduce risk and/or impacts. Both risk and mitigation measures in combination create hazard potential. Such hazard potential pass through the geographic context such as location, elevation and proximity, and various social fabrics i.e. socio-economic factors, risk perceptions, resiliency and built environment either moderate or enhance hazard potential. Therefore, biophysical and social vulnerability collectively produce the overall vulnerability of place. The hazard of place model explicitly focuses on location and depicts overall condition and presents various elements contributing to vulnerability of a specific geographic area (Kumpulainen, 2006).

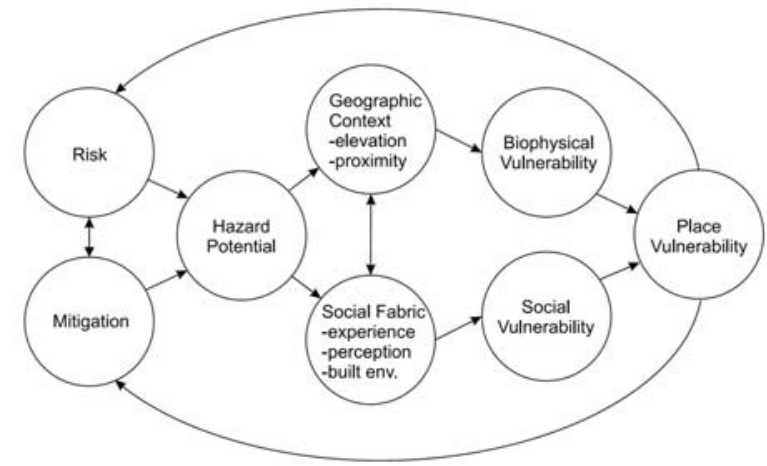

Fig. 2 The Hazards-of-Place model of vulnerability (Adopted from Cutter et al., 2003).

On the contrary, the disaster Pressure-and-Release (PAR) model considers risk-hazard approach and defines risk as a product of hazard and vulnerability, and also claims that vulnerable population's exposure is the main reason of disaster occurring (Blaikie, et al., 1994; Wisner, et al., 2004). Additionally, hazard is considered as a physically driven problem that can be mitigated by eradicating root causes of vulnerability. Such root causes are for example 'economic, demographic and political processes', which affect allocation and distribution of resources between different groups. Dynamic pressure transforms such economic and political process in local situation, for example migration. Finally, unsafe condition is the specific form of vulnerability is expressed in time and space, is the result of root causes and dynamic pressure.
Therefore, unsafe condition in one hand and physical exposure to natural hazard on the other are the main reasons of occurring disaster. Authors also argued that hazards are mostly a physically produced problem that can be mitigated by eradicating the root causes of vulnerability.

Nevertheless, in view of these differential perspectives and contexts of vulnerability in hazard discourse, it requires holistic approach to analyze vulnerability by integrating physical and social dimensions together for instance absence of basic social services, lack of properties, lack of access to credit facility, the presence of ethnic and political discrimination, pollution of air and water resources, lack of literacy and nonexistence of educational amenities (Wilches-Chaux, 1989; Lavell, 1992; Cardona, 1993; Maskrey, 1994; Cardona, 1996; Lavell 1996; Mansilla, 1996).

\section{Entitlement and Vulnerability}

Entitlement based literature of vulnerability is exclusively focused on the social realm of institutions, human well-being, class structure, social status, gender and so on. Entitlements are the real or prospective resources available to individuals based on their own production, assets or mutual arrangements (Adger, 2006). In the entitlement theory, vulnerability to food security is linked with economic and institutional factors. Therefore, food insecurity is an outcome of human activity, which can be reduced by modified human behaviour and political interventions (Adger, 2003). The theory of entitlements is an explanation for the causes of famine was developed in the early 1980s, with a notion that shortfall in production was due to drought, flood or pest (Sen, 1981; Sen, 1984). In addition, entitlements are 'the set of alternative commodity bundles that a person can command in a society using the totality of rights and opportunities that he or she faces' (Sen, 1984). In actual fact, vulnerability to shocks occurs when people have insufficient real income and wealth, or if there is breakdown in other earlier endowments. Bohle, et al.,. (1994) opined that vulnerability could be seen as a space defined by political economy, entitlement, and empowerment. Following Sen's idea, Watts and Bohle (1993) have emphasized on hunger, whereas geographers wanted to discuss theoretically the space of vulnerability considering the cause and effect issues. Primary causes of hunger are the failure of distribution of entitlement and of fundamental needs of society (Sen, 1984). On the other hand, Chambers (1989) considered vulnerability as synonym of poverty. Poverty denotes the unachieved needs and limitations of access to 
resources, while vulnerability refers to the lack of capacity to safeguard oneself and survive against environmental extremes (Chambers, 1989).

However, above mentioned approaches of vulnerability research put emphasis on empowerment (Watts and Bohle, 1993). Such approaches are directly allied with the theories of Sen on entitlements, functioning's and the expansion of capacities (Sen, 1981, 1993, 1999). Therefore, to empower and entitle a person means providing him capability to use his freedom and to enhance his capacities (Sen, 1993). However, the reverse is vulnerability, that is, the lessening of capacities and of the 'power' of action and realization. On the basis of these considerations, Watts and Bohle (1993) argue that the prescriptive and normative response to vulnerability is to reduce exposure, enhance coping capacity, strengthen recovery potential and bolster damage control (i.e. minimize destructive consequences) via private and public means.' The advantage of the entitlements approach is that it can be used to explain situations where populations have been vulnerable to famine even where there are no absolute shortages of food or obvious environmental drivers at work. Therefore, famines and other crises occur when entitlements fail (Adger, 2006).

\section{Vulnerability in Human Ecology}

Human ecology is sometimes called political ecology tradition within analysis of vulnerability to natural hazard which lays in human adjustment (Cutter, 1996; Hufschmidt, 2011). In this realm, Sen's (1990) concepts of entitlements and capabilities have worked as the foundation and presented a theoretical link to research on poverty alleviation and food security (Bohle, et al., 1994; Kelly and Adger, 2000; Alwang, et al., 2001). Likewise, Bohle, et al., (1994) opined that vulnerability may be considered as a "space" surrounded by political economy, entitlements, and empowerment (table 2). However, Adger (2006) argued that in the hazard management, dominance of engineering approaches failed to engage with the political and structural causes of vulnerability within the society. Therefore, human ecologists attempted to explain why the poor and marginalized have been most at risk from natural hazards (Hewitt, 1983; Watts, 1983). Considering this, Hewitt (1997) termed it as 'the human ecology of endangerment' and highly criticized the technocratic approach of traditional hazard research. Human ecology or political ecology approach of vulnerability research is deeply rooted in structurilist and neo-Marxist thought (Liverman, 1994). However, contemporary vulnerability research on political ecology or political economy is regarded as analysis of social and economic process, with interactive scales of cause and effect, and of social variation (Eakin and Lures, 2006). Therefore, few basic questions came forward such as why are particular population vulnerable? How they become vulnerable? And more importantly and specifically who is vulnerable? (Ribot, et al., 1996). Fordham (2003) answers such questions that poor people use to live in risky areas and specifically women are at risk of environmental hazards and less likely to recover after a hazardous event. Therefore, these population groups often remain vulnerable to environmental hazards.

However, political-ecology and political-economy approach of vulnerability research is synonymous though few conceptual differences are identified by several scholars. Political ecology tradition investigates vulnerability considering the wide-ranging processes of institutional and environmental change. This tradition also put emphasis on political economy approach considering the significance of scale, politics, and socio-economic process for explaining humanenvironment interactions and outcomes. On the other hand, political-economy approach of vulnerability analysis has a tendency to represent the explanatory capacity of political process, and political ecologist emphasis on fair consideration of both biophysical and social dynamics with specifically focusing on representation of these dynamics in policy and decision making process (Adger, et al., 2001; Liverman, 2001; Hufschmidt, 2011). Moreover, both perceptions give emphasis on the political dimensions of vulnerability and highlight social disparities and conflicts within the societies. This approach is more biased on the issues of power than conventional risk-hazard approaches (Liverman, 2001).

\section{Conflict, War and Vulnerability}

In most cases people experience vulnerability in the world comes from the perception of insecurity. Insecurity at its most basic level is not only the lack of secured food availability and supply, and of well-being, rather it also derived from war and conflict (Adger, 2006). Therefore, Hewitt $(1994,1997)$ opines that violence and the 'disasters of war' have been continual sources of danger for societies. In the past century, almost half of the all reported famine was due to war, violence or conflict. In addition, war and civil conflict often aggravate natural hazard impacts. The incidence of war and civil conflict; and the disturbing amplifies in economic marginalization and social disparity associated globalization are all at the present being coupled with environmental causes and the production 
and lessening of climate vulnerability in local places (Bohle, 2001; Vogel and O’Brien, 2004; Barnett and Adger, 2005). Moreover, uncertainties still exists such as social conflict and diseases outbreak with climate (Matthew, et al., 2003; Patz, et al., 2005). In this regard, O’Brien, et al.,'s (2004) double exposure model presents interesting idea of superimposing stressors on a population to identify vulnerability. Moreover, the perceptions of vulnerability related to war or conflicts are basically different in that of food insecurity; displacement and violence to create vulnerabilities are deliberately acts to carry out towards political ends (Hewitt, 1994, 1997).

\section{Livelihood and Vulnerability}

Sustainable livelihoods and vulnerability to poverty tradition is considered as a successor to vulnerability as entitlement failure. It complements the hazards-based approaches through conceptualization and measurement of the links between risk and well-being at the individual level (Alwang, et al., 2001; Adger and Winkels, 2006). A sustainable livelihood refers to the well-being of a person or household (Ellis, 2000) and comprises the capabilities, assets and activities that lead to well-being (Chambers and Conway, 1992; Allison and Ellis, 2001). Vulnerability in this context refers to the susceptibility to circumstances that makes unable to sustain a livelihood. In addition to this, the key focus is on consumption of poor households as a manifestation of vulnerability (Dercon, 2004). In this approach, vulnerability is seen as the interaction between social dynamics and socio-ecological system. For instance, livelihood diversification and specialization is key issue in vulnerability to drought in Kenya and Tanzania (Eriksen, et al., 2005). The authors also show that women are excluded from particular high-value activities; therefore, vulnerability is reproduced within certain parts of social systems through deep structural elements (Eriksen, et al., 2005). Similarly, Eakin (2005) shows for Mexican farmers that diversity is vital to avoid vulnerability and that investment in commercial high yielding irrigated agriculture can exacerbate vulnerability compared to a farming strategy based on maize which is more sensitive to drought. It is the multi-level interactions between system components such as livelihoods, social structures and agricultural policy; that determine system vulnerability. Likewise, Reid and Vogel (2006) conducted a regional assessment study based on sustainable livelihood framework and found that multiple stressors increase vulnerability of resource poor and rural societies in developing countries.

Table 2 Evolution of the Concept of Vulnerability in Different Disciplines

\begin{tabular}{|c|c|c|}
\hline Vulnerability approach & Objectives & Sources \\
\hline \multicolumn{3}{|l|}{ Antecedents } \\
\hline $\begin{array}{l}\text { Vulnerability to famine } \\
\text { and food insecurity }\end{array}$ & $\begin{array}{l}\text { Developed to explain vulnerability to famine in the absence } \\
\text { of shortages of food or production failures. } \\
\text { Described vulnerability as a failure of entitlements and } \\
\text { shortage of capabilities. }\end{array}$ & $\begin{array}{l}\text { Sen (1981); Swift (1989); Watts and Bohle } \\
\text { (1993) }\end{array}$ \\
\hline Vulnerability to hazards & $\begin{array}{l}\text { Identification and prediction of vulnerable groups, critical } \\
\text { regions through likelihood and consequence of hazard. } \\
\text { Applications in climate change impacts. }\end{array}$ & $\begin{array}{l}\text { Burton, et al., (1978, 1993); Smith (1996); } \\
\text { Anderson and Woodrow (1998); Parry and } \\
\text { Carter (1994) }\end{array}$ \\
\hline Human ecology & $\begin{array}{l}\text { Structural analysis of underlying causes of vulnerability to } \\
\text { natural hazards. }\end{array}$ & $\begin{array}{l}\text { Hewitt (1983); O’Keefe, et al., (1976); Mustafa } \\
\text { (1998) }\end{array}$ \\
\hline Pressure and Release & $\begin{array}{l}\text { Further developed human ecology model to link discrete } \\
\text { risks with political economy of resources and normative } \\
\text { disaster management and intervention. }\end{array}$ & $\begin{array}{l}\text { Blaikie, et al., (1994); Winchester (1992); } \\
\text { Pelling (2003); Wisner, et al., (2004) }\end{array}$ \\
\hline \multicolumn{3}{|l|}{ Successors } \\
\hline $\begin{array}{l}\text { Vulnerability to climate } \\
\text { change and variability }\end{array}$ & $\begin{array}{l}\text { Explaining present social, physical or ecological system } \\
\text { vulnerability to (primarily) future risks, using wide range } \\
\text { of methods and research traditions. }\end{array}$ & $\begin{array}{l}\text { Klein and Nicholls (1999); Smit and Pilifosova } \\
\text { (2001); Smith, et al., (2001); Ford and Smit } \\
\text { (2004); O’Brien, et al., (2004) }\end{array}$ \\
\hline $\begin{array}{l}\text { Sustainable livelihoods } \\
\text { and vulnerability to } \\
\text { poverty }\end{array}$ & $\begin{array}{l}\text { Explains why populations become or stay poor based on } \\
\text { analysis of economic factors and social relations. }\end{array}$ & $\begin{array}{l}\text { Morduch (1994); Bebbington (1999); Ellis } \\
\text { (2000); Dercon (2004); Ligon and Schechter } \\
\text { (2003); Dercon and Krishnan (2000) }\end{array}$ \\
\hline $\begin{array}{l}\text { Vulnerability of social- } \\
\text { ecological systems }\end{array}$ & $\begin{array}{l}\text { Explaining the vulnerability of coupled human } \\
\text { environment systems. }\end{array}$ & $\begin{array}{l}\text { Turner, et al., (2003a, b); Luers, et al., (2003); } \\
\text { Luers (2005); O’Brien, et al., (2004) }\end{array}$ \\
\hline
\end{tabular}

Source: Adopted from Adger, 2006.

Sustainable livelihood analysis appeared as way of lessening chronic poverty by identifying the dynamics of social and environmental relations at the household level (Scoones, 1998). It is recognized as a useful tool in environmental change research by easing the discrimination of vulnerable populations based on their 
assets and entitlements, identification of assets essential for coping/adapting to risk, and finally relating livelihood strategies to the opportunities and constrains of the broader institutional and bio-physical environment (Kelly and Adger, 2000). Broad and dynamic process of economic and social change is highlighted as sources of uncertainty, inequity and risk (O’Brien and Leichenko, 2001). V'asquez-L'eon, et al., (2003) has presented the role of resource policy, ethnicity, and class about farmers' differential adaptive capacities to safeguard livelihood from stress in the both side of Maxico boarder. Likewise, Eakin (2003, 2005) explains how neoliberal policy reforms create uncertainties in resource access, and changed farmer's choices and narrow down their flexibility to combat climatic stress. Adger (1999) presents poverty and dependency of livelihood on climate sensitive sectors as a proxy for household sensitivity to climatic perturbation among Vietnamese coastal communities.

\section{Vulnerability in Socio-ecological System}

It is true that the origin of vulnerability is in disaster and entitlement theories, but now a day there is a newly emerging approach of research with advance methods of system-oriented thinking to understand vulnerability in a holistic way in natural and social system is termed as socio-ecological system (Adger, 2006). This research approach depicts vulnerability as a possession of a social-ecological system, and seeks to elaborate the mechanisms and processes in an integrated way, and represents a conceptual development in analysis (Turner, et al., 2003a). Furthermore, the approach does not focus on multiple results from a single physical stress or perturbation, rather it seeks to analyze the main components of vulnerability i.e. exposure, sensitivity, and resilience of a bonded system at certain spatial scale. In the mean time, it also seeks to quantify and make clear both the links to other scales and to quantify the impact of action to cope and responsibility on other elements of the system; such as, the degree of exposure of ecological components or communities (Turner, et al., 2003b). Moreover, this interdisciplinary and integrative nature of the framework is part of a wider effort to identify science that supports goals of sustainability (Kates, et al., 2001) and that also is reflected in other system-oriented vulnerability research. For example, Liverman (1990) developed vigorous integrated methods for vulnerability assessment focusing on interaction between the properties of social and ecological system. It is considered as the pioneer work where she focused on vulnerability to drought in Mexico. Liverman (1990) argued that for integrative approaches based on comparative quantitative assessment of the drivers of vulnerability to drought reveals that irrigation and land tenure have the greatest impact on the incidence of vulnerability to drought making collectively owned ejido land more susceptible. Thus, using diverse sources of quantitative data, this study showed the places and the people, and the drivers within the socialecological system that led to vulnerability (Liverman, 1990).

\section{Vulnerability to Climate Change}

A newly emerged paradigm of vulnerability research is vulnerability to climate change impacts and risk. Climate change literature on vulnerability has unique distinctions with others in terms of using widely accepted terms as an integral part of its scientific agenda. In fact, climate change is a classic multi-scale global problem; which is characterizes by involving infinitively diverse actors, multiple stressors and multiple time scales (Adger, 2006). A number of earlier research based on their findings suggest that climate change impacts will significantly increase trouble on those population that are already vulnerable to climatic extreme events such as cyclone, storm surge, salinity intrusion and so on. It is also fact that the impact of projected (and increasingly observed) changes that are attributable to global climate change will adversely affect those population in future making them more vulnerable to climate change impacts. In addition, it is true for both developed and developing world that the groups who are already marginalized bear a disproportionate burden of climate impacts (Stott, et al., 2004; Kovats, et al., 2005; Poumadere, et al., 2005; O’Brien, 2006). In this regard, Intergovernmental Panel on Climate Change (IPCC) has become an authoritative source that sets agendas and acts as a legitimizing device for research. The IPCC defines vulnerability within the third assessment report (McCarthy, et al., 2001) as 'the degree, to which a system is susceptible to, or unable to cope with the adverse effects of climate change, including climate variability and extremes. Vulnerability is a function of the character, magnitude, and rate of climatic variation to which a system is exposed, its sensitivity, and its adaptive capacity.' It is therefore defined as a characteristic of a system and as a function of exposure, sensitivity and adaptive capacity.

Vulnerability research on climate change discourse has wide range of applications. For example, Adger (2006) opines that knowing vulnerability lies in applying an integrative, coupled human-environment approach to the interactions between social dynamics with the socio-ecological system, and how such dynamics form 
the resilience of various systems. In this regard, Leichenko and O'Brien (2002) mention that climate change and globalization work jointly to increase exposure of farmers to new and unforeseen circumstances in Africa. Besides, interaction between climate change and globalization considerably change the way of farmers coping with climatic variability and also change the adaptation strategies as well. Moreover, Turner, et al., (2003b) employed vulnerability analysis in more common perspective of global environmental change and sustainability science, and identified a number of vital questions that identifies vulnerable people and locations to multiple environmental changes. Wilbanks and Kates (2010) opines for increase in adaptive capacity to climate change and advocates for integration of natural hazard, sustainability, and community and regional resilience research with in the broader framework of vulnerability research. Similarly, Ziervogel, et al., (2006) provides simple definition of vulnerability and examines various degrees of susceptibility of people and/or environment to harm caused by various external stressors. The authors pointed out several issues such as exposure to stressors (i.e. hazards), ecosystem and human system's internal ability to cope with, recover from, and adopt with external perturbations. Moreover, such issues are directly linked with system's sensitivity, resilience, or adaptive capacity. Besides, Mosser (2010) identifies an array of important research needs and argues for capacity building and comprehensive changes in the inducement structure for different fields to employ in more practice and policy relevant study to relate climate change, vulnerability, and adaptation strategies

The present study also identifies that use of the term vulnerability in climate change discourse has two different meaning. For example O’Brien, et al., (2004) identified it as an 'end-point' and a 'straight-point' interpretation of vulnerability. Considering such 'endpoint' and 'straight-point' interpretation of vulnerability, Smit, et al., (1999) and Burton, et al., (2002) identified two types of adaptation research in climate change realm. End-point interpretation of vulnerability represents the expected net impacts of a specified level of global climate change with possible adaptation options and is consistent with integrated and risk-hazard approach. On the other hand, straight-point interpretation is consistent with political economy approach, and focuses on the internal side of vulnerability, for example reducing socio-economic vulnerability to any climatic hazard. In addition, this approach mainly put emphasis on prioritizing adaptation policy and broader social development. Table 3 presents two types of interpretations of vulnerability in climate change research.

Table 3 Two Interpretation of Vulnerability in Climate Change Science

\begin{tabular}{|l|l|l|}
\hline & \multicolumn{1}{|c|}{ End-point interpretation } & \multicolumn{1}{c|}{ Starting-point interpretation } \\
\hline Root problem & Climate change & Social vulnerability \\
\hline Policy context & $\begin{array}{l}\text { Climate change mitigation, compensation, } \\
\text { technical adaptation }\end{array}$ & Social adaptation, sustainable development \\
\hline Illustrative policy question & $\begin{array}{l}\text { What are the benefits of climate change } \\
\text { mitigation? }\end{array}$ & $\begin{array}{l}\text { How can the vulnerability of societies to climatic } \\
\text { hazards be reduced? }\end{array}$ \\
\hline $\begin{array}{l}\text { Illustrative research } \\
\text { question }\end{array}$ & $\begin{array}{l}\text { What are the expected net impacts of climate } \\
\text { change in different regions? }\end{array}$ & $\begin{array}{l}\text { Why are some groups more affected by climatic hazards } \\
\text { than others? }\end{array}$ \\
\hline $\begin{array}{l}\text { Vulnerability and adaptive } \\
\text { capacity }\end{array}$ & Adaptive capacity determines vulnerability & Vulnerability determines adaptive capacity \\
\hline $\begin{array}{l}\text { Reference for adaptive } \\
\text { capacity }\end{array}$ & Adaptation to future climate change & Adaptation to current climate variability \\
\hline Starting point of analysis & Scenarios of future climate hazards & Current vulnerability to climatic stimuli \\
\hline Analytical function & Descriptive, positivist & explanatory, normative \\
\hline Main discipline & Natural sciences & Social sciences \\
\hline Meaning of “vulnerability” & $\begin{array}{l}\text { Expected net change for a given level of global } \\
\text { climate change }\end{array}$ & $\begin{array}{l}\text { Susceptibility to climate change and variability as } \\
\text { determined by socio- economic factors }\end{array}$ \\
\hline Vulnerability approach & Integrated, risk-hazard & Political economy \\
\hline Reference & Mccarthy, et al., (2001) & Adger (1999) \\
\hline
\end{tabular}

(Adopted from O’ Berin, et al., 1999; Butrton, et al., 2002; Fussel and Klein, 2006; Fussel, 2007)

\section{Vulnerability in Geographical Research}

A number of disciplines use the term vulnerability. Among these, only the common though having contested meaning is human-environment relationship. In this regard, human geography plays a major disciplinary legacy to theorize vulnerability to global environmental change, natural hazards, food security and entitlement failure and so on (Adger, 2006). Various extreme natural events such as floods, droughts, earthquakes, tornados, hurricanes, landslides are studied in various disciplines with different perspectives. However, geographers studied these as 
natural hazards with specific risk of occurrence, producing disasters potentials to the various dimensions and intensity of these dangers (Hogan and Maradola, 2005). In this regard, geographers do not consider only bio-physical dimension but also human response and adjustment to such events (Hewitt and Burton, 1971; Burton, et al., 1978; Smith 1992). Considering the complications in vulnerability analysis, hazards and disaster research in geography began to incorporate various factors from both bio-physical and social process of an event, its impacts on environment, society and individual level, and individual, collective as well as organizational decisions, choices and adaptation strategies (Hogan and Maradola 2005). Contributions of 'geographers' and 'ecological school' from 1930 onwards is regarded as 'social-environmental' perspective of vulnerability (Burton, et al., 1978, Mileti 1999) that afterwards stimulated the applied science approach. Since then human dimension played an important role in vulnerability research, for example vulnerability cannot be assessed without people's capacity to absorb, respond and recover from the adverse impact of the extreme event (Westgate and O' Keefe 1976). On the contrary, various other studies in geography considered that vulnerability as a locationally driven phenomenon, as it is a function of the nearness to the source of risk. Considering such complexity, Weischeslgartner and Bertnes (2000) have proposed the concept of the combining the elements of hazard event and human response behaviour that put together both geographic and social space in one platform. In this regard, vulnerability in geographical research is considered as a combined effect of biophysical hazard and human response in a specific geographic location (Weichselgartner, 2001).

In present time, geo-information and related technologies is instigating us to rethink our understanding about vulnerability both in theoretical and practical or applied point of views (Weichselgartner, 2001; Preston et al., 2011). Maps become an important tool to present vulnerability because of its increasing use among geographers, urban and regional planners, environmental management specialist, geologist, hydrologist and other experts (Preston et al., 2011). Similarly, Weichselgartner (2001) for example measured hazard, exposure, preparedness, prevention and response in quantitative manner. Each factor is assessed by means of mapable indicators which obviously vary according to the scale of analysis. The overlay of each themes results in the vulnerability map of specific hazard. Besides, vulnerability research in geography also considers scale of analysis such as household, community, regional, national and global, though basin and landscape are also considered. Neither physical nor social events can fully be comprehended at only any of these scales. Therefore, multi-scalar perspective is required to understand differential vulnerabilities at each scale in space and time (Preston et al., 2011). In this regard, Turner, et al., (2003a) argues that 'the strong variation in vulnerability by location, even to hazards created by global-scale processes and phenomena, however, elevates the role of “place-based” analysis'. The 'placebased' concept reveals a spatially continuous unique 'ensemble' of human and bio-physical or humanenvironment systems. Increasing involvement of multiple stakeholders in vulnerability problems in local or localized concerns presents growing consideration to such level of analysis and at the same time relates to other locations and scales of analysis (Cutter, 2010) (Figure 3).

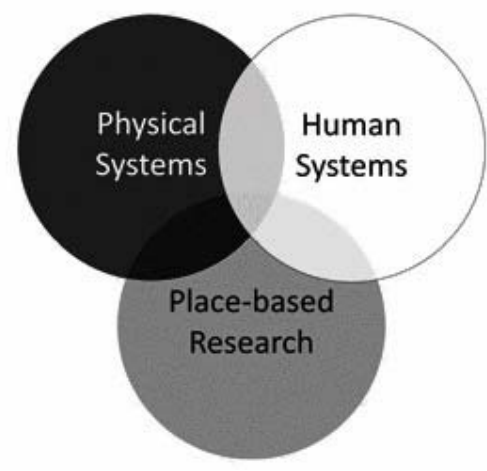

Fig. 3 Vulnerability research incorporates knowledge from the intersection of physical system, human system and place based research (Adopted from Cutter, 2010)

In actual fact, comprehending of vulnerability would come out from wholeness nature of a humanenvironment system. Hence, Turner, et al., (2003a) acknowledged this as an unrealistic goal. Therefore, it is necessary that researcher should be acquainted with the extent of the system they are considering and look for expressing its manifestation considering the scale of global, regional and local level. Besides, to accept the concept that 'vulnerability as a multi-scalar process', it is essential to understand the cascading nature of vulnerability and to recognize the process in which some factors may increase or attenuate certain events, risks and hazards (Kasperson and Kasperson, 2001). In this regard, both Turner, et al., (2003a) and Kasperson and Kasperson (2001) provide analytical methods which clearly express three spatial scales such as place, region, and world to the social and biophysical 
dimension. These methods look for identifying casual relationships together with interdependency of scales and phenomena. Moreover, there is no solitary spatial and temporal direction to events involving degradation, vulnerability, resilience and sustainability process. Therefore, owing to the involvement of diverse elements and actors in vulnerability it is very complex process to identify both causes and consequences. In this regard, Liverman (1994) argued that these focuses are overlapped that help to create vulnerability map of geographical space (where are the vulnerable persons and places?) and in social space (who are the vulnerable persons and places?). Integration of diverse components in the causal structure of vulnerability that covers different scales (local, regional, and global) and dimensions of the phenomena (social, political, economic, technological, demographic, and cultural), resulted to a more multifarious and global perspective of vulnerability. A most recent study by Eakin and Webbe (2009) presents the integration of such multiscale analysis of interaction and feedbacks between local vulnerability and wider system sustainability.

A growing body of literature is also available in geography to improve our ability to understand reason about vulnerabilities such as network analysis, geographic data acquisition and use, measuring vulnerability, evaluating temporal variations in vulnerability, and related theoretical and policy issues (Matisziw and Grubesic, 2013). Luers, et al., (2003) and Luers (2005) present a general matrix of vulnerability focusing on casual relationship between biophysical perturbation (e.g. climatic variability and change) and measurement of vulnerability outcomes (reduction in agricultural production and income) (Luers, et al., 2003). In present time, spatial indicators are also used to prepare social vulnerability index in the United States and demonstrated as a sophisticated tool for presenting various aspects of vulnerability (Cutter, et al., 2003). Besides, geographic information system and remotely sensed data are increasingly used in recent days to make spatial analysis of vulnerability and assessment of risk (Cutter, et al., 2000; Luers, et al., 2003; O’Brien, et al., 2004; Metzger, et al., 2005). In this regard, a probabilistic model is used by Peterson (2002) to examine relative resilience or vulnerability of a landscape to a change in vegetation.

Several other studies also emphasized on mapping theoretical factors of vulnerability to present spatial distribution of various capacities and sensitivities. In such types of studies selection and definition of the spatial scale of analysis is a vital concern. Moreover, importance and weight of certain indicators vary with scale of analysis and degree of data aggregation (O’Brien, et al., 2004). In this regard, O’Brien, et al., (2004) measures the exposure of Indian farm population to global climate and as well as economic change. The authors also assessed adaptive capacity and sensitivity by means of existing socio-economic and bio-physical database and combined with general circulation model. Finally, authors overlaid vulnerability map to globalization to present double exposure of population to these perturbations (O'Brien and Leichenko, 2000). To interpret the spatial relationships they employed case studies using surveys and interviews to explain the interaction of globalization and climate change on the livelihoods of particular local populations. O’Brien, et al., (2004) also point out that maps can imply abrupt rather than more realistic "fuzzy" boundaries of vulnerability across space and can mask the diversity of vulnerability states at different scales of analysis.

In addition, Murray (2011) provides a summary of network modelling approaches to understand the vulnerability of a network to damage, successive disturbance and ways of reducing network vulnerabilities. Main challenge in network analysis particularly using geographic information system is obtaining data on spatial associations that precisely denote present condition, more specifically data on emergency situations and their spatial relations which is also difficult to forecast. Population's vulnerability to certain threats can be minimized through developing well understanding of people's location, the situations they are facing, and by what means supportive infrastructure is being used. These problems are addressed by Steenbruggen, et al., (2011) where they reviewed the applicability of mobile phone data for near-real-time evaluation and monitoring of traffic conditions.

A most recent study by Xiao, et al., (2011) outlines the effect of socio-economic forces on vulnerability from a different point of view, for example measuring the change in regional vulnerability to disasters from temporal perspective. The authors compared two extreme floods of the United States (the Midwestern Floods of 1993 and 2008) in the history of 100 years by applying a case-control design to differentiate flood impacts from more common macroeconomic events. Vulnerability is a multi-dimensional phenomenon; hence there are several ways of measuring it and portraying vulnerability to specific event. Besides, Ratick and Osleeb (2011) describe various methods for developing of vulnerability index and also assess various dimensions of vulnerability to understand exposure in the Dominican Republic. 
Nonetheless, another side of vulnerability assessment is looking for impending vulnerabilities and prioritizing mitigation efforts. Considering this idea, Cova, et al., (2013) assesses community vulnerability to forest fire in the Western United States. The authors used an optimization framework for examining the possibility rising of community vulnerability to forest fire under limited road exit facilities. However, review of existing literature it reveals that geography as a discipline not only cover bio-physical dimension but also socioecological dimensions of vulnerability. Thus, geography can work as a bridge between bio-physical and socioecological dimensions of vulnerability research.

\section{Way Forward for Creating a Common Platform for Vulnerability Research}

It is often claimed that geography as a discipline is particularly appropriate for conducting a combined and interdisciplinary vulnerability research due to its exceptional capacity of problem solving. Such capacity is reasonable because of subject matter and scope of the discipline. For example, it focuses on interrelation between physical and social environment, spatial and temporal distribution, process and features of phenomena (Fuchs et al., 2011; Hualou, 2011) However, possibility of sharing methods and techniques between physical and human geographers remain debatable issue for a long time though many connections have been proposed and applied. Physical geography largely covers bio-physical phenomena (natural science), and human geography generally covers human communities (social science) (Hualou, 2011). Therefore, geography as a whole spreads over science, arts and social science in terms of both subject matter and approaches to study. Nevertheless, if geography preforms such a bridge function between bio-physical and socio-ecological realms, then both the dimensions have to be at least expanded to other fields of geographic research, which is rooted in the systematic analysis of interrelations between multiple spheres of geographic discipline (Hartshorne, 1959; Fuchs et al., 2011; Hualou, 2011). Other sources, however, argue that it is the lack in distinct theories and constructs of ideas resulting from the relatively shallowness in geographical conceptualizations that weakens the discipline in competition to related disciplines such as sociology, economy, psychology, geology and physics (Turner II 2002; Johnston 2005). Weichhart (2005) argued that human-environment interface, study on natural hazards and risk cannot be simply carried out by reintegrating natural sciences (i.e. physical geography) and social sciences (i.e. human geography), rather construction of third pillar between the two poles of science as an independent object of knowledge is characterized by specific research questions is required. However, such specific research questions may not be broadly answered by applying individual methods rooted either in physical, human, natural or social sciences (Fuchs et al., 2011). Hence, such third pillar can be a plea for an independent common platform for integrated multi-disciplinary collaborative research covering bio-physical, human, social and natural science domains (Hufschmidt, 2011).

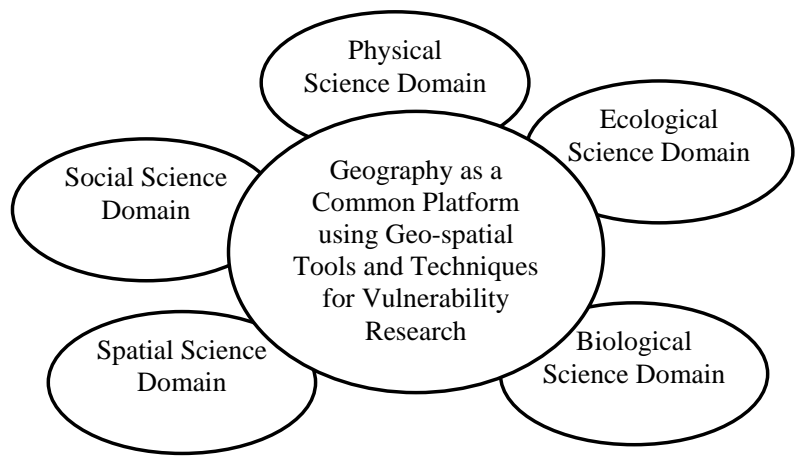

Fig. 4 Conceptual Framework for Creating Common Platform for Vulnerability Research

However, a number of complexities still exist as a barrier for creating such common platform for vulnerability research among of various research domains; more important issue is integration of such fields together through a holistic approach of interdisciplinary research collaboration (Fuchs et al., 2011). In addition, rapid expansion of the power and accessibility of geospatial tools and data has enhanced the potentials for creating a common platform for multidisciplinary and integrated vulnerability research (Preston et al., 2011; Hualou, 2011). A schematic diagram is presented in figure 4 to present how geography as a multidisciplinary research field can take this initiative to create a common platform of vulnerability research by using its geospatial tools and techniques. Moreover, this would be an initial step for any kind of multidisciplinary research endeavour in vulnerability science. Whether and to what extent geography is able to act as a mediator or negotiator or bridge between the two main groups of science and whether geography is able to link the spheres of nature and society in an integrative way in vulnerability research (Weichhart 2008) is a matter of future forms of collaboration (Fuchs et al., 2011).

\section{Concluding Remarks}

This paper presents various definitions and conceptual frameworks of vulnerability by various disciplines from 
various perspectives. Such as vulnerability to natural hazard means the characteristics of group or individual with regard to their ability to predict, cope, resist, and recover from the hazard impacts. In other words, it is the inability of an individual or a system to withstand against the perturbations of external stressors. Vulnerability can be a process or it can be a product. For example, if people live in low laying susceptible areas which are highly exposed to disaster are considered as vulnerable to disaster. Whereas, after disaster people can lose their assets and if they cannot regain pre-disaster status can also be considered as vulnerable. Similarly, people adopt different coping strategies to face the adversity. The households or individuals those adopt negative strategies such as selling of productive assets, further fall in impoverishment; and cannot regain in pre-disaster status and remain vulnerable to disaster. However, unsafe condition of an individual or bio-physical or socio-ecological system could be an alternative term of vulnerability. Moreover, such simplified understandings of vulnerability may not be equally applicable across the disciplines. Therefore, a holistic approach taking into account the identification of the unit and scale of analysis, targeted audience, objective of assessment and characteristic of vulnerability being dealt with specifically considering human-environment dimension could be helpful for decision making.

In this regard, geography can play a major disciplinary legacy to bridge between socio-ecological and biophysical dimensions of vulnerability, and can create a common platform for scholars from various disciplines to work together. If the basic concepts of place, region and scale are considered from geographical point of view could contribute positively to understand the 'totality of a system'. And more specifically, geography as a discipline can play a crucial role considering that it has in its own conventional scope both modern and contemporary, dealt within its disciplinary development with thoughts concerning very diverse knowledge's, ontologies and epistemologies. The unity of geography subsists in particular at the society-nature interface. Therefore, as a unique discipline, geography has the scope to contribute to broaden the discussion amongst the sciences in general about the creation of new paradigms and ontological and epistemological methods for operationalizing vulnerability science. Moreover, integration of different sciences and fields of knowledge together to create an independent integrated and common field will not be an easy effort. In this regard, environmental studies in general, and vulnerability study in particular, need wide-ranging standpoint as they entail problems which exhibit in a particularly convincing way the impracticality of treating the social-ecological and bio-physical aspects of phenomena separately. In addition they illustrate the importance of scalar dynamics in the methods of production, distribution and management of risks, hazards and vulnerabilities. Therefore, from the preceding discussion it can be opined that vulnerability has divergent meaning based on the objectives and research traditions. Different disciplines have their own reasons for defining, measuring and developing conceptual models for vulnerability; hence there is no reason to presume that concepts, measures and methods will be universal across the disciplines. Lessons learned from one area may not be equally suitable for all. Hence, differences between various fields could be bridged by multidisciplinary research cooperation and geography as a multidisciplinary field of study has the scope to fill up the gaps in vulnerability research among the various research traditions.

\section{References}

Adger, N. W. 1999. Social vulnerability to climate change and extremes in coastal Vietnam. World Development, 27(2):249269.

Adger, W. N. 2000. Social and ecological resilience: are they related? Progress in Human Geography. 24 (3):347-364.

Adger, W. N. 2003. Social capital, collective action and adaptation to climate change. Economic Geography. 79(4):387-404.

Adger, W. N. 2006. Vulnerability. Global Environmental Change. 16 (3):268-281.

Adger, W. N. and Kelly, P. M. 1999. Social vulnerability to climate change and the architecture of entitlements. Mitigation and adaptation strategies for global change, 4(3-4):253-266.

Adger, W. N. and Winkels, A. 2006. Vulnerability, poverty, and sustaining well-being. In: Atkinson, G., Dietz, S., Neumayer, E. (Eds.), Handbook of Sustainable Development. Elgar, Cheltenham.

Adger, W. N., Benjaminsen, T. A., Brown, K., and Svarstad, H. 2001. Advancing a political ecology of global environmental discourses. Development and change, 32(4):681-715.

Alexander, D. 1993. Natural Disasters, Chapman and Hall, New York, NY.

Allen, K. 2003. Vulnerability reduction and the community-based approach. in Pelling (ed.), Natural Disasters and Development in a Globalising World, pp.170-184.

Allison, E. H., and Ellis, F. 2001. The livelihoods approach and management of small-scale fisheries. Marine policy. 25(5):377388.

Alwang, J., Siegel, P.B., and Jorgensen, S.L. 2001. Vulnerability: A View from Different Disciplines. Discussion Paper Series No. 0115. Social Protection Unit, World Bank, Washington DC.

Anderson, M. B. 1992. Metropolitan areas and disaster vulnerability: a consideration for developing countries, in Kreimer, A. and Munasinghe, M. (Eds), Environmental Management and Urban Vulnerability, The World Bank Papers, 168, Washington, DC, pp.77-92. 
Anderson, M. B. and Woodrow, P. J. 1998. Rising From the Ashes: Development Strategies in Times of Disaster. Intermediate Technology Publications, London.

Bankoff, G., Frerks, G., and Hilhorst, D. (Eds.). 2004. Mapping vulnerability: disasters, development, and people. Earthscan.

Barnett, A. and Blaikie, P. 1994. AIDS as a long wave disaster. In: Varley, A. (Ed.), Disasters, Development, and Environment. Wiley, Chichester, pp.139-162.

Barnett, J. and Adger, W. N. 2005. Security and climate change: towards an improved understanding. Presented at Hum. Secur. Clim. Change, Asker, Nor.

Bebbington, A. 1999. Capitals and Capabilities: A Framework for Analyzing Peasant Viability, Rural Livelihoods and Poverty. World Development, 27(12): 2021-2044.

Berkes, F. and Folke, C. 1998. Rediscovery of traditional ecological knowledge as adaptive management. Ecological applications, 10(5):1251-1262.

Blaikie, P., Cannon T., Davis I., and Wisner B. 1994. At Risk: Natural Hazards, People's Vulnerability, and Disasters. Routledge, London, UK.

Bogard, W. C. 1988. Bringing social theory to hazards research: conditions and consequences of the mitigation of environmental hazards. Sociological Perspectives, 31:147-168.

Bohle, H. G. 2001. Vulnerability and criticality: perspectives from social geography. IHDP update, 2(1):3-5.

Bohle, H. G., Downing, T. E., and Watts, M. J. 1994. Climate change and social vulnerability: toward a sociology and geography of food insecurity. Global Environmental Change, 4(1):37-48.

Brooks, N. 2003. Vulnerability, risk and adaptation: A conceptual framework. Tyndall Centre for Climate Change Research Working Paper, 38:1-16.

Burton, I., Huq, S., Lim, B., Pilifosova, O., and Schipper, E. L. 2002. From impacts assessment to adaptation priorities: the shaping of adaptation policy. Climate policy, 2(2):145-159.

Burton, I., Kates, R. W. and White, G. F. 1993. The Environment as Hazard, Guildford Press, London.

Burton, I., Kates, R.W., and White, G.F. 1978. The Environment as Hazard. Guilford, New York.

Cannon, T. 1994. Vulnerability analysis and the explanation of "natural" disasters, in A Varley (ed.) Disasters, Development and Environment, John Wiley and Sons Chichester, New York, Brisbane, Toronto and Singapore, pp.13-29.

Cardona, O. D. 1993. Natural Disasters, global change and sustainable development: a strategy for reducing effects. In III Meeting of the Scientific Advisory Council for the International Geophere-Biosphere Programme, Forum on Earth System Research, ICSU, Ensenada, Baja California, Mexico.

Cardona, O. D. 1996. Manejo ambiental y prevención de desastres: dos temas asociados. Ma. A. Fernández (comp.). Ciudades en riesgo. LA RED-USAI. Lima.

Cardona, O. D. 2003. The need for rethinking the concepts of vulnerability and risk from a holistic perspective: a necessary review and criticism for effective risk management. Mapping vulnerability: Disasters, development and people, pp.17.

Chambers, R. 1989. Vulnerability, coping and policy. IDS Bulletin, 20(2):1-7.

Chambers, R. and Conway, R. 1992. Sustainable Rural Livelihood: Practical Concepts for 21th Century, Institute of Development Studies and Poverty Research Unit, University of Sussex, IDS Discussion Paper 296.
Ciurean, R. L., Schröter, D., and Glade, T. 2013. Conceptual Frameworks of Vulnerability Assessments for Natural Disasters Reduction. In Tiefenbacher, J. (ed.) Approaches to Disaster Management - Examining the Implications of Hazards, Emergencies and Disasters, Chapter 1. pp. 1-32.

Comfort, L., Wisner, B., Cutter, S., Pulwarty, R., Hewitt, K., OliverSmith, A. and Krimgold, F. 1999. Reframing disaster policy: the global evolution of vulnerable communities. Environmental Hazards, 1(1):39-44.

Cova, T. J., Theobald, D. M., Norman III, J. B., and Siebeneck, L. K. 2013. Mapping wildfire evacuation vulnerability in the western US: the limits of infrastructure. GeoJournal, 78(2):273-285.

Cutter, S. L. 1993. Living with Risk, Edward Arnold, London.

Cutter, S. L. 1996. Vulnerability to environmental hazards. Progress in Human Geography, 20(4):529-539.

Cutter, S. L. 2003. The vulnerability of science and the science of vulnerability. Annals of the Association of American Geographers, 93(1):1-12.

Cutter, S. L. 2010. Social science perspectives on hazards and vulnerability science. In Geophysical Hazards (pp. 17-30). Springer Netherlands.

Cutter, S. L., Boruff, B. J., and Shirley, W. L. 2003. Social vulnerability to environmental hazards. Social science quarterly, 84(2):242-261.

Cutter, S. L., Mitchell, J. T., and Scott, M. S. 2000. Revealing the vulnerability of people and places: a case study of Georgetown County, South Carolina. Annals of the Association of American Geographers, 90(4):713-737.

Dercon, S. (Ed.), 2004. Insurance Against Poverty. Oxford University Press, Oxford.

Dercon, S. and Krishnan, P. 2000. Vulnerability, seasonality and poverty in Ethiopia. Journal of Development Studies, 36 (6): 25-53.

Dow, K. 1992. Exploring differences in our common future (s): the meaning of vulnerability to global environmental change. Geoforum, 23(3):417-436.

Dow, K., and Downing, T. E. 1995. Vulnerability research: where things stand. National Emergency Training Centre.

Downing, T. E. 1991. Vulnerability to hunger in Africa: A climate change perspective. Global Environmental Change, 1(5): 365-380.

Downing, T. E., and Patwardhan, A. 2005. Assessing vulnerability for climate adaptation. Adaptation policy frameworks for climate change: Developing strategies, policies and measures, pp. 67-90.

Downing, T. E., Moss, S., and Pahl-Wostl, C. 2001. Understanding climate policy using participatory agent-based social simulation. In Multi-Agent-Based Simulation. Springer Berlin Heidelberg. pp. 198-213.

Eakin, H. 2003. The social vulnerability of irrigated vegetable farming households in central Puebla. The Journal of Environment and Development, 12(4):414-429.

Eakin, H. 2005. Institutional change, climate risk, and rural vulnerability: cases from Central Mexico. World Development, 33(11):1923-1938.

Eakin, H. C., and Wehbe, M. B. 2009. Linking local vulnerability to system sustainability in a resilience framework: two cases from Latin America. Climatic Change, 93(3-4):355-377.

Eakin, H., and Luers, A. L. 2006. Assessing the vulnerability of social-environmental systems. Annual Review of Environment and Resources, 31(1): 365. 
Editorial, 2006. Resilience, vulnerability, and adaptation: A crosscutting theme of the International Human Dimensions Programme on Global Environmental Change, Global Environmental Change, 16(3), 237-239.

Ellis, F. 2000. Rural Livelihood Diversity in Developing Countries. Oxford University Press, Oxford.

Emrich, C. T., and Cutter, S. L. 2011. Social vulnerability to climatesensitive hazards in the southern United States. Weather, Climate, and Society, 3(3): 193-208.

Eriksen, S. H., Brown, K., and Kelly, P. M. 2005. The dynamics of vulnerability: locating coping strategies in Kenya and Tanzania. The Geographical Journal, 171(4):287-305.

Ford, J. 2002. Vulnerability: concepts and issues. PhD Scholarly Field Paper, University of Guelph, Guelph, Canada.

Ford, J.D. and Smit, B. 2004. A framework for assessing the vulnerability of communities in the Canadian Arctic to risks associated with climate change. Arctic, 57:389-400.

Fordham, M. 2003. Gender, disaster and development: the necessity integration. In: Pelling, M. (Ed.), Natural Disasters and Development in a Globalizing World. Routledge, London, pp. 57-74.

Fuchs, S., Kuhlicke, C., and Meyer, V. 2011. Editorial for the special issue: vulnerability to natural hazards - the challenge of integration. Natural Hazards, 58(2): 609-619.

Füssel, H. M., and Klein, R. J. 2006. Climate change vulnerability assessments: an evolution of conceptual thinking. Climatic Change, 75(3):301-329.

Füssel, H. M. 2007. Vulnerability: a generally applicable conceptual framework for climate change research. Global Environmental Change, 17(2):155-167.

Gabor, T., and Griffith, T. K. 1980. The assessment of community vulnerability to acute hazardous materials incidents. Journal of Hazardous Materials, 3(4):323-333.

Gallopín, G. C. 2003. A systematic synthesis of the relations between vulnerability, hazard, exposure and impact, aimed at policy identification. ECLAC-Economic Commission for Latin America and the Caribbean (Ed.): Handbook for estimating the socioeconomic and environmental effects of disasters, Mexiko City: ECLAC.

Gallopín, G. C. 2006. Linkages between vulnerability, resilience, and adaptive capacity. Global Environmental Change, 16(3): 293-303.

Gilard, O. and Givone, P. 1997. Flood risk management: new concepts and methods for objective negotiations, in Leavesley, G.H., Lins, H.F., Nobilis, F., Parker, R.S., Schneider, V.R. and van de Ven, F.H.M. (Eds), Destructive Water: Water-caused Natural Disasters, their Abatement and Control, IAHS Press, Oxfordshire, pp. 145-55.

Gow, G.A., 2005. Policymaking for Critical Infrastructure. Ashgate, Aldershot.

Handmer, J. W., Dovers, S., and Downing, T. E. 1999. Societal vulnerability to climate change and variability. Mitigation and adaptation strategies for global change, 4(3-4):267-281.

Hewitt, K. 1983. The idea of calamity in a technocratic age. In: Hewitt, K. (Ed.), Interpretations of Calamity from the Viewpoint of Human Ecology. Allen and Unwin, Boston, pp. 3-32.

Hewitt, K. 1994. When the great planes came and made ashes of our city: towards an oral geography of the disasters of war. Antipode, 26(1):1-34.

Hewitt, K. 1997. Regions of Risk: A Geographical Introduction to Disasters. Longman, Harlow.
Hewitt, K. and Burton I. 1971. The Hazardousness of a Place: A Regional Ecology of Damaging Events. University of Toronto Press: Toronto.

Hogan, D. J. 2002. Movilidad poblacional, sustentabilidad ambiental y vulnerabilidad social: una perspectiva lationo-americana. LEFF, Enrique; EZCURRA, Exequiel; PISANTY, Irene and LANKAO, Patricia R. (comp.) La transición hacia el desarrollo sustentable. Perspectivas de América Latina y el Caribe. Mexico: INE-SEMARNAT, 161-185.

Hogan, D. J. and Marandola, Jr. E. 2005. Vulnerability and risk: between Geography and Demography. Paper presented to the seminar 'Making Sense of Vulnerability', International Geographical Union Commission on Population and Vulnerability and Department of Geography, University of Dundee, 10-11 March 2005.

Hualou, L. 2011. Disaster Prevention and Management: A Geographical Perspectives, Disaster Advances, 4(1): 3-5.

Hufschmidt, G. 2011. A comparative analysis of several vulnerability concepts. Natural hazards, 58(2): 621-643.

Ionescu, C., Klein, R.J.T., Hinkel, J., KaviKumar, K.S., and Klein, R., 2005. Towards a formal framework of vulnerability to climate change. Net Water Working Paper 2, Potsdam Institute for Climate Impact Research, Potsdam, Germany.

IPCC (Intergovernmental Panel on Climate Change), 2001. Technical summary: climate change 2001: impacts, adaptation, and vulnerability. A Report of Working Group II of the Intergovernmental Panel on Climate Change. Retrieved from http://www.grida.no/climate/ipcc tar/wg2/pdf/wg2TARtechsum.pdf.

Johnston, R., 2005. Geography-coming apart the seams? In: Castre'e N, Rogers A, Sherman D (eds) Questioning geography. Blackwell, Oxford, pp 9-25

Jones, B. and Kandel, W. A. 1992. Population growth, urbanization, disaster risk, and vulnerability in metropolitan areas: a conceptual framework, in Kreimer, A. and Munasinghe, M. (Eds), Environmental Management and Urban Vulnerability, The World Bank, Washington, DC, pp.51-76.

Kasperson, J. X., Kasperson, R. E., Turner, B. L., Hsieh, W., and Schiller, A. 2005. Vulnerability to global environmental change. The social contours of risk, 2:245-285.

Kasperson, J. X. and Kasperson, R. E. (eds.) 2001. Global Environmental Risk. London: Earthscan.

Kasperson, J.X., Kasperson, R.E., Turner, B.L., Hsieh, W. and Schiller, A. 2003. Vulnerability to Global Environmental Change. In: A. Diekman, T. Dietz, C.C. Jaeger and E.A. Rosa (Editors), The Human Dimensions of Global Environmental Change. MIT Press, Cambridge, MA.

Kasperson, R.E., Dow, K., Archer, E., Caceres, D., Downing, T.E., Elmqvist, T., Folke, C., Han, G., Iyengar, K., Vogel, C., Wilson, K., and Ziervogel, G. 2006. Vulnerable Peoples and Places, Chapter 6 of the Millennium Ecosystem Assessment: Conditions and Trends Island Press, Washington, D.C., pp 143-164.

Kates, R. W. 1985. The interaction of climate and society. In: Kates, R.W., Ausubel, H., Berberian, M. (Eds.), Climate Impact Assessment. Wiley, Chichester, UK (Chapter 1).

Kates, R.W., Clark, W.C., Corell, R., Hall, J.M., Jaeger, C.C., Lowe, I., McCarthy, J.J., Schellnhuber, H.J., Bolin, B., Dickson, N.M., Faucheux, S., Gallopin, G.C., Grubler, A., Huntley, B., Jager, J., Jodha, N.S., Kasperson, R.E., Mabogunje, A., Matson, P., Mooney, H., Moore III., B., O'Riordan, T., and Svedin, U. 2001. Environment and development: sustainability science. Science, 292:641-642. 
Kelly, P. M., and Adger, W. N. 2000. Theory and practice in assessing vulnerability to climate change andFacilitating adaptation. Climatic change, 47(4):325-352.

Klein, R. J. T. and Nicholls, R. J. 1999. Assessment of coastal vulnerability to climate change. Ambio, 28:182-187.

Kovats, R. S., Campbell - Lendrum, D., and Matthies, F. 2005. Climate change and human health: estimating avoidable deaths and disease. Risk Analysis, 25(6):1409-1418.

Kumpulainen, S. 2006. Vulnerability concepts in hazard and risk assessment. Natural and technological hazards and risks affecting the spatial development of European regions. Geological Survey of Finland, Special Paper 42, pp.65-74.

Lavell, A. 1992. Ciencias socials y desastres naturales en America Latin: Un encuentro inconcluso, Desastres Naturales, Sociedad y Proteccon Civil, COMECSO, Mexico

Lavell, A. 1996. Degradacion ambiental, riesgo y desastre urbano: Problemas y conceptos, in $M$ a Fernandes (ed) Ciudades en Riesgo, La RED, USAID, Lima

Leichenko, R. M., and O'Brien, K. L. 2002. The dynamics of rural vulnerability to global change: the case of southern Africa. Mitigation and adaptation strategies for global change, 7(1): 1-18.

Ligon, E., and Schechter, L. 2003. Measuring Vulnerability. The Economic Journal, 113(486):C95-C102.

Liverman, D. M. 1990. Drought impacts in Mexico: Climate, agriculture, technology, and land tenure in Sonora and Puebla. Annals of the Association of American Geographers, 80(1): 49-72.

Liverman, D. M. 1994. Vulnerability to global environmental change. In Environmental Risks and Hazards, ed. Cutter, S. L. Englewood Cliffs, NJ: Prentice Hall, pp. 326-42.

Liverman, D. M. 2001. Vulnerability to global environmental change. Global Environmental Risk. Tokyo/New York/Paris: UN Univ., pp. 201-16.

Luers, A. L. 2005. The surface of vulnerability: an analytical framework for examining environmental change. Global Environmental Change, 15(3):214-223.

Luers, A. L., Lobell, D. B., Sklar, L. S., Addams, C. L., and Matson, P. A. 2003. A method for quantifying vulnerability, applied to the agricultural system of the Yaqui Valley, Mexico. Global Environmental Change, 13(4):255-267.

Mansilla, E (ed). 1996. Desastres: Modelo para Armar, La RED, Lima

Maskrey, A. 1994. Comunidad y desastres en America Latin: Estrategias de intervencion. In A. Lavell (ed) Viviendo en Riesgo: Comunidades Vulnerables y Prevencion de Desastres en America Latina, La RED, Tercer Mundo Editores, Bogota

Matisziw, T. C., and Grubesic, T. H. 2013. Geographic perspectives on vulnerability analysis. GeoJournal, 78(2): 205-207.

Matthew, R. A., Gaulin, T., and McDonald, B. 2003. The elusive quest: Linking environmental change and conflict. Canadian Journal of Political Science/Revue canadienne de science politique, 36:857-878.

McCarthy, J. J., Canziani, O. F., Leary, N. A., Dokken, D. J. and White, K. S. (Eds.) 2001. Climate Change 2001: Impacts, Adaptation and Vulnerability. Cambridge University Press, Cambridge.

Metzger, M. J., Leemans, R., and Schröter, D. 2005. A multidisciplinary multi-scale framework for assessing vulnerabilities to global change. International Journal of Applied Earth Observation and Geoinformation, 7(4):253-267.
Mileti, D. 1999. Disasters by design: A reassessment of natural hazards in the United States. National Academies Press.

Mitchell, J. K. 1989. Hazards research, In Gaile, G.L. and Willmott, C.J. (Eds), Geography in America, Merill, Colombus, OH, pp. 410-24.

Morduch, J. 1994. Poverty and vulnerability. The American Economic Review, 84(2):221-225.

Moss, R. H., Brenkert, A. L., and Malone, E. L. 2001. Vulnerability to climate change: a quantitative approach. Technical Report PNNL-SA-33642, Pacific Northwest National Laboratories, Richland, WA.

Mosser, S. C. 2010. Now More Than Ever: The Need for More Societally Relevant Research on Vulnerability and Adaptation to Climate Change. Applied Geography, 30(4):464-474.

Murray, A. T. 2011. An overview of network vulnerability modeling approaches. GeoJournal, 78(2):209-221.

Mustafa, D. 1998. Structural Causes of Vulnerability to Flood Hazard in Pakistan. Economic Geography, 74(3):289-305.

Nicholls, R. J., Hoozemans, F. M., and Marchand, M. 1999. Increasing flood risk and wetland losses due to global sea-level rise: regional and global analyses. Global Environmental Change, 9:S69-S87.

O'Brien, K. 2006. Are we missing the point? Global environmental change as an issue of human security. Global Environmental Change, 16(1):1-3.

O'Brien, K. and Leichenko, R. 2001. The dynamics of vulnerability to global change. IHDP Update 2: article 4. Retrieved from http://www. ihdp.uni-bonn.de/html/publications/update /update 0102/ IHDPUpdate01 02 Obrien.html

O’Brien, K.L., Leichenko, R., Kelkarc, U., Venemad, H., Aandahl, G., Tompkins, H., Javed, A., Bhadwal, S., Barg, S., Nygaard, L. and West, J. 2004. Mapping vulnerability to multiple stressors: climate change and globalization in India. Global Environmental Change, 14(4):303-313.

O'Brien, K. L., and Leichenko, R. M. 2000. Double exposure: assessing the impacts of climate change within the context of economic globalization. Global environmental change, 10(3):221-232.

O'Brien, K., Sygna, L., and Haugen, J. E. 2004. Vulnerable or resilient? A multi-scale assessment of climate impacts and vulnerability in Norway. Climatic change, 64(1-2):193-225.

O'Keefe, P., Westgate, K., and Wisner, B. 1976. Taking the naturalness out of natural disasters. Nature, 260:566-567.

Parry, M. and Carter, T. 1994. Climate Impact and Adaptation Assessment: A Guide to the IPCC Approach. Earthscan Publication Ltd, London.

Patz, J. A., Campbell-Lendrum, D., Holloway, T., and Foley, J. A. 2005. Impact of regional climate change on human health. Nature, 438(7066):310-317.

Pelling, M. 2003. The Vulnerability of Cities, Earthscan Publication Ltd., London, UK. Pp. 46-67.

Peterson, G. D. 2002. Estimating resilience across landscapes. Conservation Ecology 6(1): 17. [online] URL:http:// www.consecol.org/ vol6/iss1/art17/

Pijawaka, K. D., and Radwan, A. E. 1985. Transportation of hazardous materials. Risk assessment and hazard management. DANG. PROP. INT. MATER. REP. 5(5):2-11.

Poumadere, M., Mays, C., Le Mer, S., and Blong, R. 2005. The 2003 heat wave in France: dangerous climate change here and now. Risk Analysis, 25(6):1483-1494. 
Preston, B. L., Yuen, E. J., and Westaway, R. M. 2011. Putting vulnerability to climate change on the map: a review of approaches, benefits, and risks. Sustainability Science, 6(2): 177-202.

Prowse, M. 2003. Towards a Clearer Understanding of 'Vulnerability' in Relation to Chronic Poverty. CPRC Working Paper No. 24, Chronic Poverty Research Centre, Institute for Development Policy and Management, University of Manchester.

Ratick, S. J., and Osleeb, J. P. 2011. Measuring the vulnerability of populations susceptible to lead contamination in the Dominican Republic: evaluating composite index construction methods. GeoJournal, 78(2):259-272.

Reid, P. and Vogel, C. 2006. Living and Responding to Multiple Stressors in Southern Africa-Glimpses from KwaZulu-Natal. Global Environmental Change, 16(2):195-206.

Ribot, J. C., Najam, A., and Watson, G. 1996. Climate variation, vulnerability and sustainable development in the semi-arid tropics. Cambridge University Press, Cambridge, United Kingdom and New York, NY, USA. pp. 13-54.

Scoones, I. 1998. Sustainable rural livelihoods: a framework for analysis. IDS Work. Pap. 72, Inst. Dev. Stud., Sussex, UK.

Sen, A. 1990. Food, economics and entitlements. The political economy of hunger, 1:34-50.

Sen, A. 1993. Capability and well-being. The quality of life, 1(9): 30-54.

Sen, A. K. 1981. Poverty and Famines: An Essay on Entitlement and Deprivation. Clarendon, Oxford.

Sen, A. K. 1984 Resources, Values and Development. Blackwell, Oxford.

Sen, A. K. 1999. Development As Freedom. Oxford University Press.

Smit, B. and Pilifosova, O. 2001. Adaptation to climate change in the context of sustainable development and equity. In: McCarthy, J.J., Canziani, O., Leary, N.A., Dokken, D.J., White, K.S. (Eds.), Climate Change 2001: Impacts, Adaptation and Vulnerability. IPCC Working Group II. Cambridge University Press, Cambridge, pp.877-912.

Smit, B., and Wandel, J. 2006. Adaptation, adaptive capacity and vulnerability. Global environmental change, 16(3):282-292.

Smit, B., Burton, I., Klein, R. J., and Street, R. 1999. The science of adaptation: a framework for assessment. Mitigation and adaptation strategies for global change, 4(3-4):199-213.

Smith, J. B., Schellnhuber, H. J. and Mirza, M. M. Q. 2001. Vulnerability to climate change and reasons for concern: a synthesis. In: McCarthy, J.J., Canziani, O., Leary, N.A., Dokken, D.J., White, K.S. (Eds.), Climate Change 2001: Impacts, Adaptation and Vulnerability. IPCC Working Group II. Cambridge University Press, Cambridge, pp.914-967.

Smith, K. 1992. Environmental Hazards: Assessing Risk and Reducing Disaster, Routledge, London.

Smith, K. 1996. Environmental Hazards: Assessing Risk and Reducing Disaster, (Second ed.) Routledge, London. Soc. Prot. Discuss. Pap. Ser.115, Soc. Prot. Unit, World Bank, Washington, DC. pp. 42.

Stabinski, L., Pelley, K., Jacob, S. T., Long, J. M., and Leaning, J. 2003. Reframing HIV and AIDS. BMJ: British Medical Journal, 327(7423):1101-1103.

Steenbruggen, J., Borzacchiello, M. T., Nijkamp, P., and Scholten, H. 2011. Mobile phone data from GSM networks for traffic parameter and urban spatial pattern assessment: a review of applications and opportunities. GeoJournal, 78(2):223-243.
Stott, P. A., Stone, D. A., and Allen, M. R. 2004. Human contribution to the European heat wave of 2003. Nature, 432(7017):610-614.

Susman, P., O’Keefe, P. and Wisner, B. 1984. Global disasters: A radical interpretation', in K Hewitt (ed) Interpretations of Calamity from the Viewpoint of Human Ecology, Allen and Unwin, Boston, pp.264-83.

Swift, J. 1989. Why are rural people vulnerable to famine? IDS Bulletin, 20(2):8-15.

Timmerman, P. 1981. Vulnerability resilience and collapse of society. A Review of Models and Possible Climatic Applications. Toronto, Canada: Institute for Environmental Studies, University of Toronto.

Turner, B. L., Kasperson, R. E., Matson, P. A., McCarthy, J. J., Corell, R. W., Christensen, L., Eckley, N., Kasperson, J. X., Luers, A., Martello, M. L., Polsky, C., Pulsipher, A. and Schiller, A. 2003a. A framework for vulnerability analysis in sustainability science. Proceedings of the National Academy of Sciences, 100(14): 8074-8079.

Turner, B. L., Matson, P. A., McCarthy, J. J., Corell, R. W., Christensen, L., Eckley, N., Hovelsrud-Broda, G. K., Kasperson, J. X., Kasperson, R. E., Luers, A., Martello, M. L., Mathiesen, S., Naylor, R., Polsky, C., Pulsipher, A., Schiller, A., Selin, H. and Tyler, N. 2003b. Illustrating the coupled human-environment system for vulnerability analysis: three case studies. Proceedings of the National Academy of Sciences, 100(14):8080-8085.

UNDRO, 1982. Natural Disasters and Vulnerability Analysis, Office of the United Nations Disaster Relief Co-ordinator, Geneva.

UNEP, 2002. Global Environment Outlook 3 -Past, Present and Future Perspectives. Earthscan Publications Ltd. London, United Kingdom.

USP, 2013. Vulnerability Mapping, University of the South Pacific, retrieved from http://www.usp.ac.fj/index.php?id=10045 viewed on 23-08-2013.

Vásquez-León, M., West, C. T., and Finan, T. J. 2003. A comparative assessment of climate vulnerability: agriculture and ranching on both sides of the US-Mexico border. Global Environmental Change, 13(3):159-173.

Vogel, C., and O'Brien, K. 2004. Vulnerability and global environmental change: rhetoric and reality. Aviso, 13:1-8.

Watts, M. 1983. On the poverty of theory: natural hazards research in context. In: Hewitt, K. (Ed.), Interpretations of Calamity for the Viewpoint of Human Ecology. Allen and Unwin, Boston, pp. 231-262.

Watts, M. J., and Bohle, H. G. 1993. Hunger, famine and the space of vulnerability. GeoJournal, 30(2): 117-125.

Watts, M. J., and Bohle, H. G. 1993. The space of vulnerability: the causal structure of hunger and famine. Progress in human geography, 17(1): 43-67.

Weichhart, P. 2008. Der Mythos vom "Bru“ckenfach". Geographische Revue, 10:59-69

Weichhart, P., 2005. Auf der Suche nach der "dritten Sa"ule”. Gibt es Wege von der Rhetorik zur Pragmatik? In: Mu“ller-Mahn D, Wardenga U (eds) Mo"glichkeiten und Grenzen integrativer Forschungsansa"tze in Physischer Geographie und umangeographie. Institut für La“nderkunde, Leipzig, pp. 109-136

Weichselgartner, J. 2001. Disaster mitigation: the concept of vulnerability revisited. Disaster Prevention and Management, 10(2):85 - 95. 
Weichselgartner, J. and Bertens, J. 2000. Natural disasters: acts of God, nature or society? On the social relation to natural hazards", in Andretta, M.A. (Ed.), Risk Analysis II, WIT Press, Southampton, pp.3-12.

Westgate, K. N. and O'Keefe, P. 1976. Some definitions of disaster, Occasional Paper 4, Disaster Research Unit, University of Bradford, Bradford.

Wilbanks, T. J., and Kates, R. W. 2010. Beyond adapting to climate change: embedding adaptation in responses to multiple threats and stresses. Annals of the Association of American Geographers, 100(4):719-728.

Wilches-Chaux, G. 1989. Desastres, ecologismo y formación profesional, Servicio Nacional de Aprendizaje (SENA), Popayan

Winchester, P. 1992. Power, Choice and Vulnerability: A Case Study in Disaster Management in South India. James and James, London.
Wisner, B., Blaikie, P., Cannon T., and Davis I., (Ed.). 2004. At risk: natural hazards, people's vulnerability and disasters. Psychology Press.

Wolf, S., Hinkel, J., Hallier, M., Bisaro, A., Lincke, D., Ionescu, C., and Klein, R. J. 2013. Clarifying vulnerability definitions and assessments using formalisation. International Journal of Climate Change Strategies and Management, 5(1):54-70.

Xiao, Y., Wan, J., and Hewings, G. J. 2011. Flooding and the Midwest economy: assessing the Midwest floods of 1993 and 2008. GeoJournal, 78(2):245-258.

Ziervogel, G., Bithell, M., Washington, R., and Downing, T. 2005. Agent-based social simulation: a method for assessing the impact of seasonal climate forecast applications among smallholder farmers. Agricultural Systems, 83(1):1-26.

Manuscript received on 2 December 2013 and revised on 14 December 2013 